\title{
Maternal obesity and risk of adverse obstetric outcomes in Malaysia
}

\section{Dear Editor,}

Obesity during pregnancy is associated with increased risk of adverse health outcomes such as gestational diabetes mellitus (GDM), hypertension and preeclampsia. ${ }^{1}$ Unlike the well-known association between maternal hyperglycaemia and pregnancy outcomes, the effect of obesity in pregnancy has drawn some controversial conclusions. ${ }^{1}$ Data are even scarcer in Southeast Asia countries. In this research, we examined prospectively the effect of obesity in pregnancy and gestational weight gain (GWG) on pregnancy outcomes.

A prospective study was conducted from October 2017 to March 2019 in 5 maternal and child health centres in Kuching, Malaysia, and was approved by the Medical Research \& Ethics Committee (MREC), Ministry of Health Malaysia. This study was also registered under the National Medical Research Register (NMRR ID: NMRR-16-2725-31652). All participants who fulfilled the study criteria were recruited after informed consent. This study received research grant from the Universiti Malaysia Sarawak Special Grant Scheme F05/ SpGS/1548/2017.

All participants in their first trimester who were more than 18 years of age underwent a $75 \mathrm{~g}$ oral glucose tolerance test (OGTT). Participants were excluded if their fasting plasma glucose was $\geq 7.0 \mathrm{mmol} / \mathrm{L}$ and $/$ or 2-hour plasma glucose was $\geq 11.1 \mathrm{mmol} / \mathrm{L}$ (undiagnosed diabetes mellitus [DM]); or fasting plasma glucose was $\geq 5.1 \mathrm{mmol} / \mathrm{L}$ and/or 2-hour plasma glucose was $\geq 8.5 \mathrm{mmol} / \mathrm{L}$ (GDM). All other participants underwent second OGTT between 24 and 28 weeks of gestation and were excluded if they were diagnosed with GDM. We also excluded participants with underlying DM, genetic disorders affecting growth or congenital anomalies, multiple pregnancy, conception using artificial insemination, or human immunodeficiency virus/Hepatitis $\mathrm{B} /$ Hepatitis $\mathrm{C}$ infection.

We divided the participants into subject or control groups based on first trimester body mass index (BMI) as weight gain during first trimester of pregnancy is negligible. ${ }^{2}$ The World Health Organization has recommended a BMI cut-off of $23 \mathrm{~kg} / \mathrm{m}^{2}$ as overweight for Asians, and $\geq 25 \mathrm{~kg} / \mathrm{m}^{2}$ as obese. Based on this, participants with a BMI of $\geq 23 \mathrm{~kg} / \mathrm{m}^{2}$ were recruited as subjects (obese group) and those with a BMI of $18.5-23 \mathrm{~kg} / \mathrm{m}^{2}$ were recruited as controls. Total GWG was calculated based on the difference between first and third trimester weight. As multiparity ( $\geq 2$ live births) is associated with higher risk of pregnancy-induced hypertension (PIH), we categorised parity of the mothers as $0-1$ live birth and $\geq 2$ live births.

Demographic data were recorded. At first trimester, the participants' weight and height were recorded for calculation of BMI. At every trimester visit, the following were recorded: (1) blood pressure (BP) using sphygmomanometer after 15 minutes of rest, (2) midstream urine for presence of proteinuria, and (3) weight. The participants were followed up until the point of delivery. Occurrence of adverse pregnancy outcomes was documented.

The outcomes measured in this study included the occurrence of PIH, pre-eclampsia, gestational age at delivery, need of induction of labour (IOL) and primary caesarean section for delivery. $\mathrm{PIH}$ is defined as new-onset hypertension $(>140 / 90 \mathrm{mmHg})$ after 20 weeks gestation without significant proteinuria. Preeclampsia is defined as systolic $\mathrm{BP}>140 \mathrm{mmHg}$, diastolic $\mathrm{BP}>90 \mathrm{mmHg}$ and proteinuria $(>1+)$ on $\geq 2$ occasions $\geq 6$ hours apart after 20 -week gestation. The need of IOL is the process of initiating labour using either pharmacological or non-pharmacological methods.

Statistical analysis was performed using SPSS version 19.0 (IBM Corp, Armonk, US). Univariate analyses were used to compare dichotomous outcomes, and Student's t-test was used to compare continuous outcomes. Multiple logistic regression models were used to evaluate outcomes, adjusting for maternal age, parity, smoking status and gestational age. Adjusted odds ratios and $95 \%$ confidence interval were calculated. A value of $P<0.05$ was considered significant.

A total of 123 obese mothers and 102 controls consented to the study. There was no significant difference in baseline demographic data (Table 1).

Obese mothers gained $6.5 \mathrm{~kg} \pm 4.0$ throughout the pregnancy over 267.8 gestational days \pm 11.0 . Non-obese mothers gained $8.4 \mathrm{~kg} \pm 3.8$ throughout the pregnancy over 268.7 gestational days \pm 7.3 . There was no significant difference in gestational age between the groups $(P=0.953)$.

The maternal outcomes are summarised in Table 2. Significantly more obese mothers developed PIH and underwent primary caesarean section compared to the control group. All subjects with PIH were given 
Table 1. Baseline demographic data

\begin{tabular}{|c|c|c|c|}
\hline & Obese $(\mathrm{N}=123)$ & Control $(\mathrm{N}=102)$ & $P$ value \\
\hline Age, mean (SD) & $30.1(5.0)$ & $28.9(4.9)$ & 0.09 \\
\hline $\begin{array}{l}\text { Education level, } \mathbf{n}(\%) \\
\text { No formal education } \\
\text { Primary } \\
\text { Secondary } \\
\text { Tertiary }\end{array}$ & $\begin{array}{c}1(0.81) \\
5(4.07) \\
73(59.35) \\
44(35.77)\end{array}$ & $\begin{array}{c}1(0.98) \\
5(4.90) \\
67(65.69) \\
29(28.43)\end{array}$ & 0.71 \\
\hline $\begin{array}{l}\text { Employment status, } \mathbf{n}(\mathbf{\%}) \\
\text { Employed } \\
\text { Unemployed }\end{array}$ & $\begin{array}{l}66(53.0) \\
57(47.0)\end{array}$ & $\begin{array}{l}61(59.0) \\
41(41.0)\end{array}$ & 0.42 \\
\hline Household income, median (IQR) & $24,000(30,000)$ & $24,000(21,900)$ & 0.37 \\
\hline $\begin{array}{l}\text { Smoking status, n (\%) } \\
\text { Yes } \\
\text { No }\end{array}$ & $\begin{array}{c}1(0.81) \\
122(99.2)\end{array}$ & $\begin{array}{c}1(0.98) \\
101(99.0)\end{array}$ & 1.0 \\
\hline $\begin{array}{l}\text { Family history of type } \mathbf{2} \text { diabetes, } \mathbf{n}(\mathbf{\%}) \\
\text { Yes } \\
\text { No }\end{array}$ & $\begin{array}{l}27(22.0) \\
96(78.1)\end{array}$ & $\begin{array}{l}14(13.7) \\
88(86.3)\end{array}$ & 0.12 \\
\hline $\begin{array}{l}\text { Family history of hypertension, } \mathbf{n}(\mathbf{\%}) \\
\text { Yes } \\
\text { No }\end{array}$ & $\begin{array}{l}52(42.3) \\
71(57.7)\end{array}$ & $\begin{array}{l}31(30.4) \\
71(69.6)\end{array}$ & 0.07 \\
\hline $\begin{array}{l}\text { Family history of cardiovascular disease, } \mathbf{n}(\mathbf{\%}) \\
\text { Yes } \\
\text { No }\end{array}$ & $\begin{array}{c}11(8.9) \\
112(91.1)\end{array}$ & $\begin{array}{c}4(3.9) \\
98(96.1)\end{array}$ & 0.18 \\
\hline Body mass index, $\mathrm{kg} / \mathrm{m}^{2}$ & $29.0(4.45)$ & $20.4(1.48)$ & $<0.001$ \\
\hline $\begin{array}{l}\text { Parity, n (\%) } \\
0-1 \\
2-4\end{array}$ & $\begin{array}{l}71(31.6) \\
52(23.1)\end{array}$ & $\begin{array}{l}66(64.7) \\
36(35.3)\end{array}$ & 0.106 \\
\hline
\end{tabular}

IOL between 37 and 40 weeks gestation. In this study, primary caesarean section is defined as the first caesarean section performed on the mother to deliver the baby regardless of parity. Reasons for primary caesarean section are outlined in Table 3. There were 4 women $(3.25 \%)$ from the obese group who developed preeclampsia and 5 required IOL; there were none from the control group for both outcomes, although the difference was not statistically significant. All 4 women with pre-eclampsia underwent caesarean section deliveries. The reasons for requiring IOL are premature rupture of membrane $(\mathrm{n}=1)$ and post-term pregnancy $(\mathrm{n}=4)$.

There was no significant association between total GWG with PIH $(P=0.73)$, pre-eclampsia $(P=0.80)$, need of $\operatorname{IOL}(P=0.14)$ and primary caesarean section $(P=0.64$ for obese group and $P=0.61$ for non-obese group). There was also no significant association between multiparity and PIH $(P=0.105)$.

The results suggest that obese mothers have higher risk of adverse pregnancy outcomes compared to non-obese mothers regardless of parity and despite no excessive GWG. Our findings show that obese mothers are more likely to develop PIH, and require primary caesarean section, with acute fetal distress as the most common reason for the surgery. More obese mothers developed pre-eclampsia, and required IOL.

Obesity is one of the known risk factors leading to PIH and pre-eclampsia. ${ }^{3,4}$ Women with PIH are at increased risk of developing pre-eclampsia, renal dysfunction and placenta abruption on top of adverse effects on the fetus. ${ }^{5}$ A large Swedish study showed that the risk of pre-eclampsia rose with maternal weight from $2.8 \%$ in lean women to $10.2 \%$ in obese women. ${ }^{6}$ Pre-eclampsia is one of the main causes of maternal and fetal morbidity and mortality in developing countries. ${ }^{7}$ Despite novel therapies being developed for preeclampsia, the only cure is to deliver the baby, followed by expulsion of the placenta. However, the decision on the optimal timing and mode of delivery depends heavily on maternal and fetal risks in continuing the pregnancy, and neonatal risk in ending the pregnancy. ${ }^{8}$

Our study found a higher caesarean section rate among obese mothers compared to controls, of which the main cause was acute fetal distress, increasingly cited 
Table 2. Univariate analysis on pregnancy outcomes between the groups

\begin{tabular}{lcc}
\hline Pregnancy outcomes & Obese, n (\%) & Control, n (\%) \\
\hline Pregnancy-induced hypertension & $8(6.5 \%)$ & $0(0 \%)$ \\
Pre-eclampsia & $4(3.3 \%)$ & 0.009 \\
Delivery via induction of labour & $5(4.1 \%)$ & 0.128 \\
Delivery via primary caesarean section & $26(21.1 \%)$ & 0.065 \\
\hline
\end{tabular}

Table 3. Reasons for primary caesarean section

\begin{tabular}{lcc}
\hline Reasons & Obese, n (\%) & Control, n (\%) \\
\hline Acute fetal distress & $17(13.8)$ \\
\hline Failed induction of labour & $3(2.4)$ & 0 \\
\hline Maternal heart disease & $2(1.6)$ & $1(1.0)$ \\
Pregnancy-induced hypertension & $4(3.3)$ \\
\hline Pre-eclampsia & $\mathbf{2 6}(\mathbf{2 1 . 1})$ \\
\hline Total
\end{tabular}

as an indication for caesarean section in the last two decades. Many caesarean deliveries have retrospectively been found to be unnecessary, raising the question whether continuous cardiotocography interpretation could have limitations in predicting true adverse neonatal outcomes. ${ }^{9,10}$ Previous studies demonstrated that increasing BMI is strongly associated with caesarean section rate. However, these studies could have been affected by several confounding variables, such as underlying GDM, DM and hypertension, which were excluded from our study.

Earlier studies identified GWG as an independent risk factor for adverse pregnancy outcomes in obese women and those with GDM. ${ }^{11,12}$ However, in our study, although non-obese mothers had significantly higher GWG compared to the obese group, it did not affect the pregnancy outcome. This is likely because GWG in our subjects was within the recommended weight gain range, unlike in earlier data.

Our study suggests the need to prevent obesity in pregnancy, despite not having other cardiovascular risk factors or excessive GWG. Obesity in pregnancy should receive equal emphasis as other disorders in pregnancy such as DM and chronic hypertension. However, effective weight loss in pregnancy cannot be done safely without possible adverse effects on the growing fetus. ${ }^{13}$ Hence, we encourage active intervention for weight loss to achieve a healthy BMI pre-conception. Public education and awareness via health promotion and campaigns are needed to recognise obesity in pregnancy as a risk for adverse obstetric outcomes.

Our study is limited by the lack of data on lifestyle and dietary pattern of the subjects, which could have affected GWG. Moreover, as this study was conducted in Sarawak, the findings may not be generalisable to the population of Malaysia at large.

Nevertheless, to the best of our knowledge, this is the first prospective study done in Malaysia that examined the association between obesity in pregnancy on adverse pregnancy outcomes. These findings also add to current available evidence on the importance of classifying obesity in pregnancy as high-risk pregnancy, which requires appropriate antenatal care to reduce adverse obstetric outcomes. Unlike previous studies that also included late-bookers, which may falsely raise the number of obese subjects, we included only women from the first trimester to better reflect their prepregnancy weight. We did not use maternal memory of pre-pregnancy weight to avoid inaccurate recall and bias. We used BMI to categorise our subjects as it is a better indicator of body composition instead of weight alone. Moreover, we excluded women who developed GDM in late pregnancy through a repeated OGTT.

In conclusion, obesity is an independent risk for adverse obstetric outcomes, especially PIH and in requiring primary caesarean section, even without excessive GWG. Further well-designed prospective studies examining this association are crucial. 


\section{Acknowledgements}

The authors would like to thank the Director General of Health Malaysia for the permission to publish this paper, Ms Nadirah bt Sulaiman for assisting with statistical analysis, and members of the Obesity in Pregnancy Study Group for collection of data. The members are: Dr Sabrina Lukas, Dr Lenny M. Hamden, Dr Juslina bt Omar, Dr Jennet Michael, Associate Professor Dr Mardiana bt Kipli, Professor Dr Lee Gaik Chan, Dr Janet Hii and their respective teams.

\section{REFERENCES}

1. Valsamakis G, Kyriazi EL, Mouslech Z, et al. Effect of maternal obesity on pregnancy outcomes and long-term metabolic consequences. Hormones 2015;14:345-57.

2. Usha Kiran TS, Hemmadi S, Bethel J, et al. Outcome of pregnancy in a woman with an increased body mass index. BJOG 2005;112:768-72.

3. Gaillard R, Steegers EA, Hofman A, et al. Associations of maternal obesity with blood pressure and the risks of gestational hypertensive disorders. The Generation R Study. J Hypertens 2011;29:937-44.

4. Jensen DM, Damm P, Sørensen B, et al. Pregnancy outcome and prepregnancy body mass index in 2459 glucose-tolerant Danish women. Am J Obstet Gynecol 2003;189:239-44.

5. Leeman L, Dresang LT, Fontaine P. Hypertensive Disorders of Pregnancy. Am Fam Physician 2016;93:121-7.

6. Cnattingius S, Bergström R, Lipworth L, et al. Prepregnancy weight and the risk of adverse pregnancy outcomes. N Engl J Med 1998; 338:147-52.

7. Saleem S, McClure EM, Goudar SS, et al. A prospective study of maternal, fetal and neonatal deaths in low- and middle-income countries. Bull World Health Organ 2014;92:605-12.
8. Mol BWJ, Roberts CT, Thangaratinam S, et al. Pre-eclampsia. Lancet 2016;387:999-1011.

9. Dellinger EH, Boehm FH, Crane MM. Electronic fetal heart rate monitoring: early neonatal outcomes associated with normal rate, fetal stress, and fetal distress. Am J Obstet Gynecol 2000;182:214-20.

10. Gangwar R, Chaudhary S. Caesarean Section for Foetal Distress and Correlation with Perinatal Outcome. J Obstet Gynaecol India 2016;66(Suppl 1):177-80.

11. Jensen DM, Ovesen P, Beck-Nielsen H, et al. Gestational weight gain and pregnancy outcomes in 481 obese glucose-tolerant women. Diabetes care 2005;28:2118-22.

12. Macrì F, Pitocco D, di Pasquo E, et al. Gestational weight gain as an independent risk factor for adverse pregnancy outcomes in women with gestational diabwetes. Eur Rev Med Pharmacol Sci 2018;22:4403-10.

13. Gunatilake RP, Perlow JH. Obesity and pregnancy: clinical management of the obese gravida. Am J Obstet Gynecol 2011; 204:106-19.

Huai Heng Loh, ${ }^{1}{ }_{M R C P}(U K)$, Haslinda Taipin, ${ }^{2}{ }_{R N}$, Asri $\underline{\text { Said, }},{ }^{1}$ MMed (UKM)

${ }^{1}$ Faculty of Medicine and Health Sciences, Universiti Malaysia Sarawak, Malaysia

${ }^{2}$ Malaysia Ministry of Health Training Institute, Kota Kinabalu, Malaysia

Correspondence: Dr Huai Heng Loh, Faculty of Medicine and Health Sciences, Universiti Malaysia Sarawak, Jalan Datuk Muhammad Musa, 94300 Kota Samarahan, Sarawak, Malaysia.

Email: hhloh@unimas.my 